\title{
Adrenal Histoplasmosis in Immunocompetent Patients Presenting as Adrenal Insufficiency
}

\author{
Smeeta GAJENDRA, Rashi SHARMA, Shalini GOEL, Ruchika GOEL, Lipika LIPI, Hemanti SARIN, \\ Mridula GULERIA, Ritesh SACHDEV
}

Department of Pathology \& Laboratory Medicine, Medanta the Medicity, GURGAON, INDIA

\begin{abstract}
Objective: Histoplasmosis is an infectious disease caused by the dimorphic fungus Histoplasma capsulatum, endemic in central and eastern states of United States, South America and Africa. India is considered to be non-endemic area for histoplasmosis. Disseminated histoplasmosis may affect almost all systems. Disseminated histoplasmosis with asymptomatic adrenal involvement has been described in immunocompromised patients; whereas isolated adrenal involvement with adrenal insufficiency as the presenting manifestation of the disease is rare.

Material and Method: Twelve patients from a non-endemic area with adrenal histoplasmosis, who were immunocompetent and diagnosed as adrenal histoplasmosis by cytology/histopathology between January 2012 to December 2014 were studied. 18F-FDG PET/CT (fluorodeoxyglucose positron emission tomography/computed tomography) was used to assess the extent of involvement.

Results: There were a total of 12 immunocompetent males (mean age: 56.9 years). Ten patients had bilateral adrenal involvement and two had a unilateral left adrenal mass. All the patients had histopathologically/cytologically proven adrenal histoplasmosis. Two patients had simultaneous histoplasmosis of other sites, one in the epiglottis and the other in the alveolus. 18F-FDG PET/CT was performed in 10 patients showing high FDG uptake in the adrenals. All these patients received Amphotericin B and/or Itraconazole treatment that led to symptomatic improvement.

Conclusion: A diagnosis of invasive fungal infection requires a high index of suspicion, especially in immunocompetent patients who present with nonspecific symptoms, clinical signs, laboratory and radiological features that can resemble adrenal neoplasms. Clinical specimens must be sent for cytopathology/histopathology together with fungal culture for a definite diagnosis and appropriate management.
\end{abstract}

Key Words: Histoplasmosis, Immunocompetence, Adrenal insufficiency, PAS reaction, Grocott methenamine silver

\section{INTRODUCTION}

Histoplasmosis is a granulomatous infectious disease caused by the dimorphic fungus Histoplasma capsulatum, endemic in central and eastern states of United States, South America and Africa. India is considered to be a non-endemic area for histoplasmosis. The spectrum of this illness varies from asymptomatic infection to widespread disseminated disease, more prevalent in immunocompromised patients. Histoplasmosis occurs in $0.65 \%$ of cases among non-AIDS patients who develop systemic mycosis (1). It is primarily a pulmonary disease; however, disseminated infection may affect almost all systems including the reticuloendothelial system, gastrointestinal tract, renal tract, central nervous system, bone marrow and adrenal glands (2). Isolated adrenal gland involvement is rare, usually involving bilateral adrenals. It is more common in males. We describe 12 immunocompetent patients who had adrenal histoplasmosis presenting as adrenal insufficiency.

(Turk Patoloji Derg 2016, 32:105-111)

Received : 05.10.2015 Accepted : 24.12.2015

\section{MATERIALS and METHODS}

This was a retrospective analysis of 12 cases of histoplasmosis involving the adrenals in immunocompetent males admitted to a tertiary care hospital of North India from January 2012 to December 2014. All of them had cytological/histopathological evidence of histoplasmosis. Fungal morphology was delineated using the GomoriGrocott methenamine silver (GMS), and Periodic Acid Schiff (PAS) stains. 18F-FDG PET/CT (fluorodeoxyglucose positron emission tomography/computed tomography) was performed to assess the extent of involvement.

\section{RESULTS}

The patients were male with a mean age of presentation of 56.9 years (range: 44-72 years). All patients were immunocompetent, presented with nonspecific symptoms and clinical signs, and underwent adrenocortical function testing, which revealed adrenal insufficiency. Ten out of 12 cases $(83.4 \%)$ had bilateral adrenal masses and two had a

Correspondence: Ritesh SACHDEV

Department of Pathology \& Laboratory Medicine, Medanta the Medicity,

Sector - 38, Gurgaon, HARYANA 122001 INDIA

E-mail: sachdev05@gmail.com Phone: +981 1836806 
unilateral left adrenal mass. Two patients had simultaneous histoplasmosis of other sites such as the epiglottis and lung. On CT scan, adrenal masses were 1.5 to $6.6 \mathrm{~cm}$ in diameter. 18F-FDG PET/CT was done in 10 patients showing high FDG uptake in the adrenals (Figure 1). Four cases showed mediastinal/abdominal lymphadenopathy. Five cases were diagnosed by endoscopic ultrasound guided fine needle aspiration, 5 cases by histopathological examination of the adrenal and one case by bone marrow examination. In one case (Case 5), both histopathology of epiglottis and endoscopic ultrasound guided fine needle aspiration of the left adrenal were performed. Endoscopic ultra-sound (EUS) guided fine needle aspiration cytology (FNAC) smears showed scattered stripped epithelial cells of adrenal gland origin in a dense amorphous background with scattered lipid globules, debris, areas of dense necrosis and mixed population of numerous inflammatory cells. Ziehl-Neelsen stain showed no acid-fast bacilli. On PAS and GMS, numerous capsulated yeast-like fungal organisms with uneven budding were evident, morphologically resembling Histoplasma species (Figure 2A,B). Histopathology of the adrenal gland revealed extensive areas of necrosis surrounded by palisades of histiocytic cells (Figure 3A) with focal areas showing epithelioid morphology with giant cell granuloma (Figure 3B). Many of the histiocytic cells showed yeast forms of 2-4 micron in size with a perinuclear halo confirming closely to the morphology of Histoplasma (Figure 3C,D). PAS (Figure 3E) and GMS (Figure 3F) stain highlighted the fungal structures, further confirming the diagnosis of Histoplasmosis. The antifungal drugs itraconazole, and/or amphotericin B were administered in all cases. These patients showed clinical improvement and were followed up for 0.5 to 2 years. The cases are summarized in Table I.
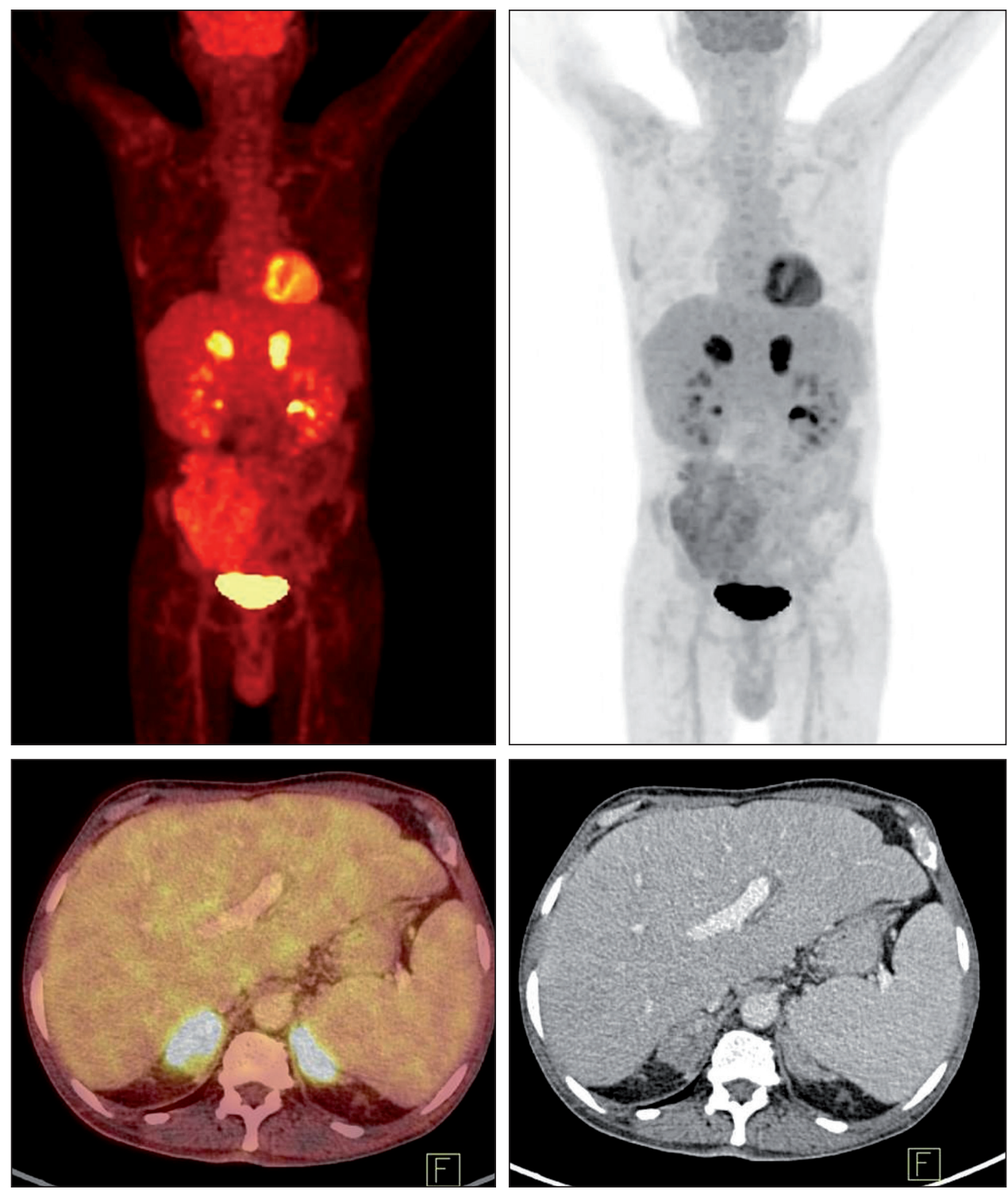

Figure 1: 18F-FDG PET/CT scan showing high FDG uptake in bilateral adrenals. 
Table I: The profile of the twelve cases with adrenal histoplasmosis

\begin{tabular}{|c|c|c|c|c|c|c|c|c|c|}
\hline No & $\begin{array}{l}\text { Age/ } \\
\text { Sex }\end{array}$ & Clinical Presentation & $\begin{array}{c}\text { Adrenal } \\
\text { involvement }\end{array}$ & AI & $\begin{array}{c}\text { Clinical } \\
\text { Diagnosis }\end{array}$ & HP & $\begin{array}{l}\text { PET } \\
\text { Scan }\end{array}$ & Therapy & $\begin{array}{c}\text { Follow up } \\
\text { Duration (m) }\end{array}$ \\
\hline 1 & $56 / \mathrm{M}$ & $\begin{array}{c}\text { Lt renal mass+B/ } \\
\mathrm{L} \text { adrenal } \\
\text { mass+Hepatomegaly }\end{array}$ & $\mathrm{B} / \mathrm{L}$ & + & Malignancy & Adrenal & $\begin{array}{l}\text { High } \\
\text { uptake in } \\
\text { adrenals }\end{array}$ & $\begin{array}{l}\text { IV A+ } \\
\text { oral I }\end{array}$ & $\mathrm{CI} / 6$ \\
\hline 2 & $58 / \mathrm{M}$ & PUO+Mediastinal LN & $\mathrm{U} / \mathrm{L}(\mathrm{Lt})$ & + & $\mathrm{TB}$ & $\begin{array}{c}\text { EUS guided } \\
\text { FNAC Lt } \\
\text { Adrenal }\end{array}$ & $\begin{array}{l}\text { High } \\
\text { uptake in } \\
\text { adrenals }\end{array}$ & $\begin{array}{l}\text { IV A+ } \\
\text { oral I }\end{array}$ & $\mathrm{CI} / 24$ \\
\hline 3 & $52 / \mathrm{M}$ & $\begin{array}{l}\text { Anorexia+generalized } \\
\text { weakness+ } \\
\text { Splenomegaly+ } \\
\text { retroperitoneal, } \\
\text { periportal LN } \\
\end{array}$ & $\mathrm{B} / \mathrm{L}$ & + & Malignancy & $\begin{array}{c}\text { EUS guided } \\
\text { FNAC Lt } \\
\text { Adrenal }\end{array}$ & $\begin{array}{l}\text { High } \\
\text { uptake in } \\
\text { adrenals }\end{array}$ & $\begin{array}{l}\text { IV A+ } \\
\text { oral I }\end{array}$ & $\mathrm{CI} / 12$ \\
\hline 4 & $70 / \mathrm{M}$ & $\begin{array}{l}\mathrm{B} / \mathrm{L} \text { lower limb } \mathrm{DVT}+ \\
\text { recurrent } \mathrm{PE}\end{array}$ & $\mathrm{B} / \mathrm{L}$ & + & $\mathrm{TB}$ & $\begin{array}{c}\text { EUS guided } \\
\text { FNAC Lt } \\
\text { Adrenal } \\
\end{array}$ & $\begin{array}{l}\text { High } \\
\text { uptake in } \\
\text { adrenals }\end{array}$ & $\begin{array}{c}\text { IV A+ } \\
\text { oral I }\end{array}$ & $\mathrm{CI} / 25$ \\
\hline 5 & $72 / \mathrm{M}$ & Chronic lung disease & $\mathrm{B} / \mathrm{L}$ & + & & $\begin{array}{c}\text { HP } \\
\text { epiglottis+ } \\
\text { US guided } \\
\text { FNAC Lt } \\
\text { Adrenal } \\
\end{array}$ & $\begin{array}{l}\text { High } \\
\text { uptake in } \\
\text { adrenals }\end{array}$ & $\begin{array}{l}\text { IV A+ } \\
\text { oral I }\end{array}$ & $\mathrm{CI} / 18$ \\
\hline 6 & $56 / \mathrm{M}$ & PUO & $\mathrm{U} / \mathrm{L}(\mathrm{Lt})$ & + & $\begin{array}{l}\text { Adrenal } \\
\text { abscess }\end{array}$ & $\begin{array}{c}\text { EUS guided } \\
\text { FNAC Lt } \\
\text { Adrenal }\end{array}$ & ND & $\begin{array}{c}\text { IV A+ } \\
\text { oral I }\end{array}$ & $\mathrm{CI} / 23$ \\
\hline 7 & $54 / \mathrm{M}$ & Adrenal mass & $\mathrm{B} / \mathrm{L}$ & + & Malignancy & $\begin{array}{c}\text { EUS guided } \\
\text { FNAC Lt } \\
\text { Adrenal }\end{array}$ & $\begin{array}{l}\text { High } \\
\text { uptake in } \\
\text { adrenals }\end{array}$ & $\begin{array}{c}\text { IV A+ } \\
\text { oral I }\end{array}$ & $\mathrm{CI} / 4$ \\
\hline 8 & $44 / \mathrm{M}$ & $\begin{array}{c}\text { Fever+progressive } \\
\text { weight loss+anorexia }\end{array}$ & $\mathrm{B} / \mathrm{L}$ & + & $\mathrm{TB}$ & $\begin{array}{l}\text { Bone } \\
\text { marrow }\end{array}$ & $\begin{array}{l}\text { High } \\
\text { uptake in } \\
\text { adrenals }\end{array}$ & $\begin{array}{c}\text { IV A+ } \\
\text { oral I }\end{array}$ & $\mathrm{CI} / 10$ \\
\hline 9 & $65 / \mathrm{M}$ & $\begin{array}{c}\text { Fever+skin } \\
\text { pigmentation +weight } \\
\text { loss+ paraaortic, celiac, } \\
\text { mesenteric LN }\end{array}$ & $\mathrm{B} / \mathrm{L}$ & + & $\begin{array}{c}\text { ACTH } \\
\text { secreting } \\
\text { B/L adrenal } \\
\text { tumor } \\
\end{array}$ & Adrenals & $\begin{array}{l}\text { High } \\
\text { uptake in } \\
\text { adrenals }\end{array}$ & $\begin{array}{l}\text { IV A+ } \\
\text { oral I }\end{array}$ & $\mathrm{CI} / 20$ \\
\hline 10 & $49 / \mathrm{M}$ & Rt Lung lesion & $\mathrm{B} / \mathrm{L}$ & + & $\mathrm{Ca}$ & Lung & $\begin{array}{l}\text { High } \\
\text { uptake in } \\
\text { adrenals }\end{array}$ & $\begin{array}{c}\text { IV A+ } \\
\text { oral I }\end{array}$ & $\mathrm{CI} / 12$ \\
\hline 11 & $53 / \mathrm{M}$ & Skin pigmentation & $\mathrm{B} / \mathrm{L}$ & + & Adrenal TB & Adrenal & $\begin{array}{l}\text { High } \\
\text { uptake in } \\
\text { adrenals }\end{array}$ & $\begin{array}{c}\text { IV A+ } \\
\text { oral I }\end{array}$ & $\mathrm{CI} / 20$ \\
\hline 12 & $54 / \mathrm{M}$ & $\begin{array}{c}\text { Metabolic } \\
\text { encephalopathy with } \\
\text { acute AI+ paraaortic } \\
\text { \&aortocaval LN }\end{array}$ & $\mathrm{B} / \mathrm{L}$ & + & $\begin{array}{c}\text { Primary } \\
\text { adrenal } \\
\text { insufficiency }\end{array}$ & Adrenal & ND & $\begin{array}{c}\text { IV A+ } \\
\text { oral I }\end{array}$ & $\begin{array}{c}\text { Therapy just } \\
\text { started }\end{array}$ \\
\hline
\end{tabular}

AI: Adrenal insufficiency, M: Male, Lt: Left, Rt: Right, B/L: Bilateral, U/L: Unilateral, PUO: Pyrexia of unknown origin, A: Amphotericin, I: Itraconazole, LN: Lymph node, CI: Clinical improvement, IV: Intravenous, TB: Tuberculosis, HP: Histopathology, Ca: Carcinoma, DVT: Deep venous thrombosis, PE: Pulmonary embolism, ND: Not Determined. 

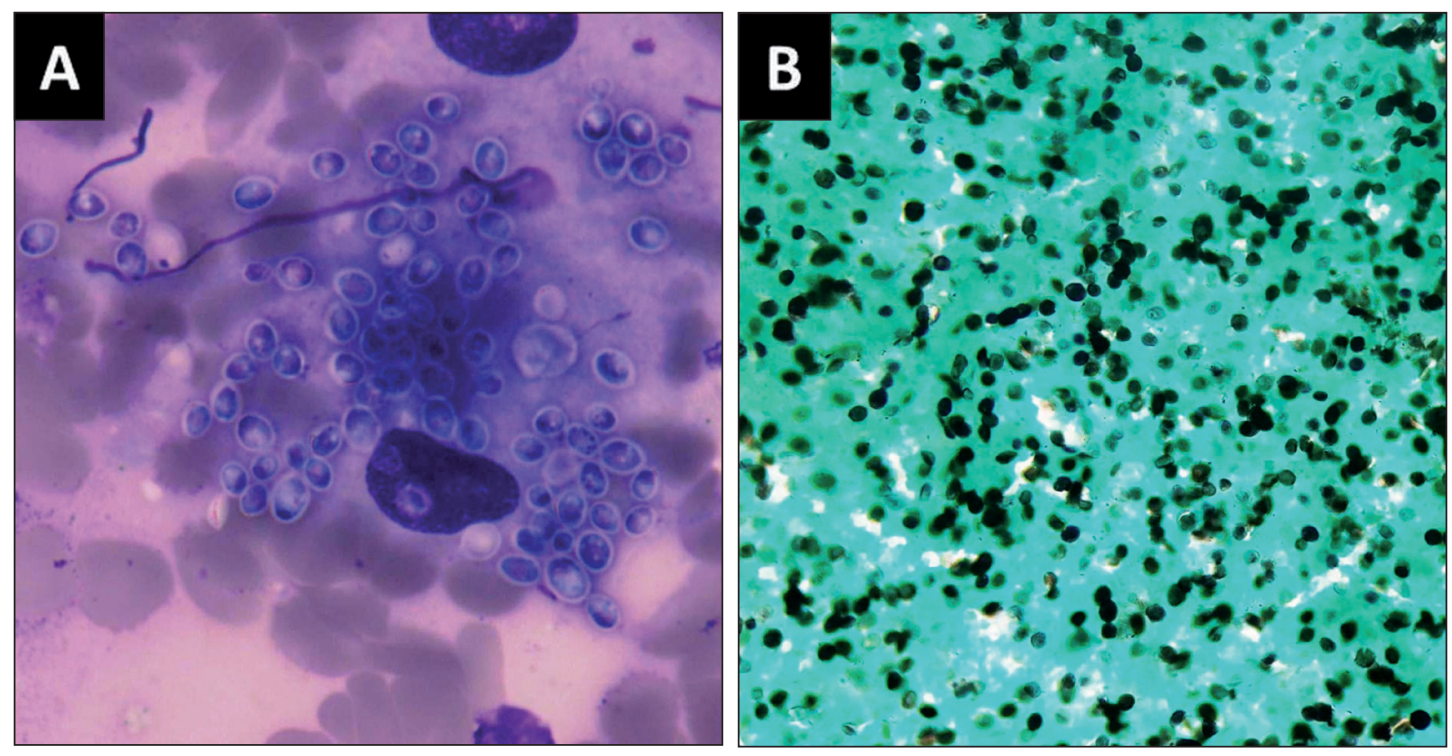

Figure 2: Cytology smear. A) Multiple capsulated Histoplasma in histiocytic cells (Giemsa; x100). B) Histoplasma yeasts with GMS positivity (GMS; x40).

\section{DISCUSSION}

Adrenal infection is most frequently caused byhematological dissemination. The adrenal glands are also a frequent site of metastasis. Mycobacterium tuberculosis (TB) is the most common pathogen causing adrenal infection. Fungal infection of the adrenal gland is rare, but occurs commonly in immunocompromised patients such as AIDS patients, transplant recipients, those with hematologic malignancies and patients on corticosteroids. Histoplasma species are the commonest fungi involving the adrenals. The range of adrenal involvement by histoplasmosis is varied as: (a) mildest form characterized by isolated cortical foci of parasitized macrophages, (b) extensive caseative necrosis with enlargement of bilateral adrenals, (c) extensive infarction, (d) granulomatous replacement of adrenals, and (e) calcified mass lesion that may mimic tubercular or metastatic lesions (2-4).

In histoplasmosis, the spectrum of illness ranges from chronic course of disease to acute fatal infection. Most patients have nonspecific symptoms and clinical signs. It usually presents as a self-limiting pulmonary infection, which is usually asymptomatic or can be associated with mild influenza-like symptoms. The progressive disseminated form of the disease is rare and occurs mainly in immunocompromised patients. The disseminated form may affect almost all systems, including the reticuloendothelial system, lungs, gastrointestinal tract, renal tract, central nervous system, bone marrow and adrenal glands. Adrenal involvement by histoplasmosis may occur during the active course of dissemination or may evolve many years after the disease become inactive. Histoplasmosis presenting as asymptomatic bilateral adrenal enlargement has been described previously (5-7) but unilateral adrenal involvement is rare. In our study, a unilateral adrenal mass was seen in two cases at the time of presentation. Adrenal histoplasmosis has a wide spectrum of clinical manifestations including chronic fatigue, weight loss, anorexia and fever. It may lead to adrenal insufficiency by progressive destruction of bilateral adrenal glands. Primary adrenal insufficiency/Addison's disease occurs in 5-71\% of adrenal histoplasmosis cases and is the commonest cause of death (3). These patients exhibit fever, malaise, orthostatic hypotension, nausea and vomiting with hyperkalemia and hyponatremia (7). Tuberculosis and fungal infections (such as histoplasmosis, coccidiodomycosis, blastomycosis) are two broad categories that are important as causes of adrenal insufficiency and tuberculosis is the most common cause. Physical examination may reveal hepatosplenomegaly or lymphadenopathies. In our study on 12 cases, organomegaly and lymphadenopathies were revealed in 2 and 4 cases, respectively.

In disseminated histoplasmosis, abdominal imaging usually reveals mild to moderate hepatomegaly with or without splenomegaly. Abdominal lymphadenopathy and focal hypodense lesions in the spleen have also been described. The patients with adrenal histoplasmosis reveal unilateral or bilateral adrenal masses of varied imaging features. On ultrasonography, the lesions may show a uniformly hypoechoic to heterogenous echopattern with preservation of normal adrenal gland outlines. The range of CT findings include minimal enlargement with faint flecks of calcium, moderate enlargement with focal low attenuation nodules, and massive enlargement with large 

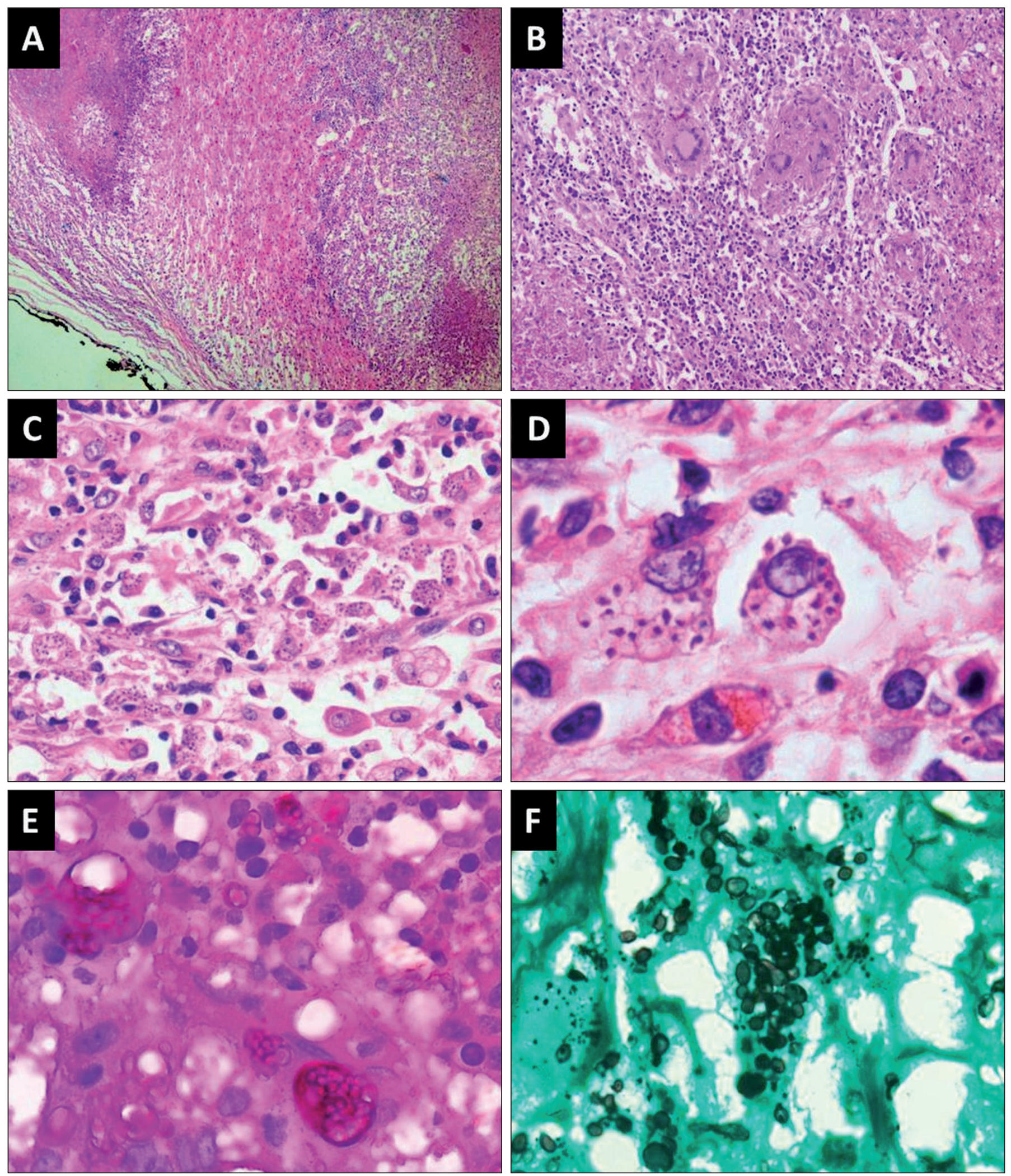

Figure 3: A) Histopathology showing extensive areas of necrosis surrounded by palisades of histiocytic cells (H\&E; x10). B) Focal areas showing granuloma (H\&E; x20). C-D) Many of the histiocytic cells showing Histoplasma (H\&E; x100 and x400). E) Histoplasma yeasts with PAS positivity (PAS; x200). F) Histoplasma yeasts with GMS positivity (GMS; x200). 
areas of necrosis or dense calcification (8). However, the typical CT findings of adrenal histoplasmosis are bilateral symmetrical adrenal enlargement with low-density areas of necrosis and hemorrhage. Other infectious causes such as paracoccidioidomycosis are indistinguishable from histoplasmosis on imaging, and metastasis may mimic infection as central necrosis is common in both conditions. In our cases, all adrenal masses were hypodense on CT, and homogeneous in eight but heterogeneous in four. Heterogeneous enhancement was seen in four, homogeneous enhancement in four and no enhancement in four patients.

Diagnosis involves performing enzyme immunoassay on urine, serum cerebrospinal fluid and bronchoalveolar lavage fluid. Diagnosis of disseminated disease can also be done on bone marrow examination, as in one of our cases (case 8). Diagnostic accuracy has improved greatly with the use other laboratory tests such as serology, complement fixation, a precipitation test, latex particle agglutination test, agar-gel double immune-diffusion test, radioimmunoassay, polymerase chain reaction and microscopy (9). However, the gold standard for diagnosis of histoplasmosis is tissue culture (10). On fine needle aspiration cytology, Histoplasma is commonly seen within the cytoplasm of the macrophages on a necrotic background and exhibits narrow based budding or can also be seen extra-cellularly as the fragile cytoplasm of the macrophages may get disrupted at the time of preparing smears (11). Characteristic histopathology of adrenal histoplasmosis includes demonstrating fungal elements in the glands. There may be localized mononuclear cells infiltrating developing granulomata with multinucleated giant cells. Often yeasts are detected in areas of caseating necrosis. Yeasts show uninucleate hyaline spherules or ovules 2 to $4 \mu \mathrm{m}$ size. Yeasts have a single bud attached by a narrow base and are often seen in clusters. By using PAS and GMS stain, yeasts can be seen in necrotic areas. Our six cases were diagnosed on cytology; five cases were diagnosed on histopathological examination of the adrenal and one case on bone marrow examination.

The differential diagnoses of bilateral adrenomegaly are metastasis, lymphoma, adrenal haemorrhage, sarcoidosis and infections that include histoplasmosis, tuberculosis, cryptococcosis, coccidioidomycosis and blastomycosis (12). Bilateral involvement with adrenal enlargement is common in malignancy, but adrenal insufficiency is very uncommon, accounting to $<1 \%$ of cases of adrenal malignancy. In three of our cases, there was suspicion of malignancy due to the presence of significantly bulky bilateral adrenal glands forming a conglomerate soft tissue density mass with heterogeneous enhancement and central necrosis on CT abdomen. On imaging, histoplasmosis may mimic malignancy because central necrosis can be seen in both conditions. However, central hypodensity and peripheral rim enhancement of the adrenals is more common in tuberculosis and histoplasmosis. Adrenal FNAC along with histopathology, culture, polymerase chain reaction, and urine antigen can confirm the diagnosis of histoplasmosis and can differentiate it from other conditions.

The majority of individuals who are asymptomatic with histoplasmosis recover spontaneously and do not require any specific treatment. Chronic and acute severe cases require treatment (4). Correct preoperative diagnosis of adrenal histoplasmosis may obviate the need for surgery while early treatment with antifungal therapy may restore adrenal reserve. In patients with adrenal insufficiency, treatment with corticosteroids may be promptly started without a complete laboratory diagnosis of adrenal insufficiency from blood cortisol level and low ACTH-stimulated cortisol responses (13). Among patients with adrenal insufficiency, a large proportion requires replacement therapy, although reversal of adrenal dysfunction has been described after prolonged antifungal treatment. The recommended anti-fungal treatment is amphotericin B for critically ill hospitalized patients. This had to be replaced by itraconazole later on because of nephrotoxicity. Itraconazole is well tolerated and has excellent central nervous system penetration. Ketoconazole may be used in milder presentations. Recurrence has been described as long as nine years after cessation of treatment, and therefore treatment duration of one to two years reduces the risk of relapse.

In conclusion, adrenal histoplasmosis does occur in immunocompetent patients and has to be considered in the differential diagnosis of bilateral/unilateral adrenal masses presenting with adrenal insufficiency. A diagnosis of invasive fungal infection is critical and requires a high index of suspicion, especially in immunocompetent patients who have presented with nonspecific symptoms, clinical signs, and laboratory and radiological features resembling adrenal neoplasms. Clinical specimens must be sent for histopathology and fungal culture for a definite diagnosis and an appropriate management. 


\section{REFERENCES}

1. Larbcharoensub N, Srisuma S, Ngernprasertsri T, Aroonroch R, Chongtrakool P, Santanirand P, Chirachariyavej T, Sirikulchayanonta V. Invasive fungal infection in Ramathibodi Hospital: A ten-year autopsy review. J Med Assoc Thai. 2007;90:2630-7.

2. Wheat LJ. Histoplasmosis: A review for clinicians from nonendemic areas. Mycoses. 42006;9:274-82.

3. Koene RJ, Catanese J, Sarosi GA. Adrenal hypofunction from histoplasmosis: A literature review from 1971 to 2012. Infection. 2013;41:757-9.

4. Larbcharoensub N, Boonsakan P, Aroonroch R, Rochanawutanon M, Nitiyanant P, Phongkitkarun S, Poonvutikul S, Watcharananan SP, Ngarmukos C. Adrenal histoplasmosis: A case series and review of the literature. Southeast Asian J Trop Med Public Health. 2011;42:920-5.

5. Bhansali A, Das S, Dutta P, Walia R, Nahar U, Singh SK, Vellayutham P, Gopal S. Adrenal histoplasmosis: Unusual presentations. J Assoc Physicians India. 2012;60:54-8.

6. Kumar N, Singh S, Govil S. Adrenal histoplasmosis: Clinical presentation and imaging features in nine cases. Abdom Imaging. 2003;28:703-8.
7. Kauffman CA. Histoplasmosis: A clinical and laboratory update. Clin Microbiol Rev. 2007;20:115-32.

8. Wilson DA, Muchmore HG, Tisdal RG, Fahmy A, Pitha JV. Histoplasmosis of the adrenal glands studied by CT. Radiology. 1984;150:779-83.

9. Grover SB, Midha N, Gupta M, Sharma U, Talib VH. Imaging spectrum in disseminated histoplasmosis: Case report and brief review. Australas Radiol. 2005;49:175-8.

10. Hage CA, Wheat LJ. Histoplasmosis. In: FaucivAS, Braunwald E, Kasper DL, editors. Harrison's principles of internal medicine. Vol 1. 17th ed. New York: McGraw-Hill; 2008: 1244-7.

11. Eloubeidi MA, Luz LP, Crowe DR, Snowden C, Morgan DE, Arnoletti PJ. Bilateral adrenal gland enlargement secondary to histoplasmosis mimicking adrenal metastases: Diagnosis with EUS-guided FNA. Diagn Cytopathol. 2010;38:357-9. doi: $10.1002 / \mathrm{dc} .21210$.

12. Vyas S, Kalra N, Das P J, Lal A, Radhika S, Bhansali A, Khandelwal N. Adrenal histoplasmosis: An unusual cause of adrenomegaly. Indian J Nephrol. 2011;21:283-5.

13. Chedid MF, Chedid AD, Geyer GR, Chedid MB, Severo LC. Histoplasmosis presenting as addisonian crisis in an immunocompetent host. Rev Soc Bras Med Trop. 2004;37:60-2. 